\title{
Technical reliability of shipboard technologies for the application of alternative fuels
}

Lukas Popp ${ }^{1,2}$ and Karsten Müller $r^{1,2,3^{*}}$

\begin{abstract}
Background: Naval traffic is highly dependent on depleting fossil resources and causes significant greenhouse gas emissions. At the same time, marine transportation is a major backbone of world trade. Thus, alternative fuel concepts are highly needed. Different fuels such as ammonia, methanol, liquefied natural gas and hydrogen have been proposed. For some of them, first prototype vessels have been in operation. However, practical experience is still limited. Most studies so far focus on aspects such as efficiency and economics. However, particularly in marine applications, reliability of propulsion systems is of utmost importance, because failures on essential ship components at sea pose a huge safety risk. If the respective components lose their functionality, repair can be much more challenging due to large distances to dockyards and the complicated transport of spare parts to the ship. Consequently, evaluation of reliability should be a core element of system analysis for new marine fuels.
\end{abstract}

Results: In this study, reliability was studied for four potential fuels. The analysis involved several steps: estimation of overall failure rates, identification of most vulnerable components and assessment of criticality by including severity of fault events. On the level of overall failure rate, ammonia is shown to be very promising. Extending the view over a pure failure rate-based evaluation shows that other approaches, such as LOHC or methanol, can be competitive in terms of reliability and risk. As different scenarios require different weightings of the different reliability criteria, the conclusion on the best technology can differ. Relevant aspects for this decision can be the availability of technical staff, high-sea or coastal operation, the presence of non-naval personnel onboard and other factors.

Conclusions: The analysis allowed to compare different alternative marine fuel concepts regarding reliability. However, the analysis is not limited to assessment of overall failure rates, but can also help to identify critical elements that deserve attention to avoid fault events. As a last step, severity of the individual failure modes was included. For the example of ammonia, it is shown that the decomposition unit and the fuel cell should be subject to measures for increasing safety and reducing failure rates.

Keywords: Resilience, Dependability, Energy storage, FMEA

*Correspondence: karsten.mueller@uni-rostock.de

${ }^{3}$ Institute of Technical Thermodynamics, University of Rostock, Albert-Einstein-Str. 2, 18059 Rostock, Germany

Full list of author information is available at the end of the article

\section{Background}

Ships are an energy efficient way of transporting goods. Yet, current marine transport is still mainly based on fossil fuels and particularly marine fuel oil. Their combustion is linked to emissions of greenhouse gases and other pollutants. There is a strong public pressure to make shipping independent of depleting fossil resources and enhance their environmental sustainability [1]. Potential original author(s) and the source, provide a link to the Creative Commons licence, and indicate if changes were made. The images or other third party material in this article are included in the article's Creative Commons licence, unless indicated otherwise in a credit line to the material. If material is not included in the article's Creative Commons licence and your intended use is not permitted by statutory regulation or exceeds the permitted use, you will need to obtain permission directly from the copyright holder. To view a copy of this licence, visit http://creativecommons.org/licenses/by/4.0/. The Creative Commons Public Domain Dedication waiver (http://creativeco mmons.org/publicdomain/zero/1.0/) applies to the data made available in this article, unless otherwise stated in a credit line to the data. 
solutions proposed in this regard are the use of liquefied natural gas (LNG) [2], methanol [3], ammonia [4] or hydrogen $[5,6]$.

Most authors evaluate energy efficiency or economics of these alternative marine fuels, while the aspect of reliability still requires closer examination. However, a failing propulsion system or power provision can have tremendous effects on a ship. While conventional maritime diesel engines are a proven technology, most of the new technologies lack experience with longtime fieldtests in this specific application scenario. A comprehensive comparison of the different solutions is the basis for an informed decision. It is crucial to amend the energetic, economic and ecological analyses by an evaluation of their dependability and risks associated with potential failures.

There are already a few studies dealing with aspects related to reliability of alternative maritime fuels. Most of these works deal with LNG-based systems and have a focus on hazard risks. The respective safety research shows that after leakage, LNG tends to accumulate in lower sections due to its high density and the heat flux from burning LNG clouds reaches levels sufficient for third-level burns [7]. Relevant aspects with regard to safety of LNG transport by ship are among others the loading at the terminal [8]. For LNG-diesel dual fuel engine there is also a study on failure probability for an inland waterway transportation scenario [9]. The authors focused on the engine itself and identified nine safetycritical factors, including failures of oil pumps, pressure limiting valves and speed regulation.

Etemad and Choi studied methanol dual fueled ships regarding safety issues related to the alternative fuel and concluded that there is no fire, explosion or other safety problem, which prohibits the use of methanol as a marine fuel [10]. Existing works regarding reliability of ammonia as a fuel also focus on safety issues and not on operability. Especially the high toxicity is stressed in these studies [11]. Inanloo and Tansel studied ammonia flames and explosion in the context of cargo transport [12]. However, a report from the DTU on safety assessment of ammonia as transportation fuel concludes that, as long as appropriate safety measures are taken, the utilization of ammonia as a fuel would not cause greater risks than the fuels currently used [13].

Hydrogen is widely discussed as a fuel for several transport applications. Public perception of hydrogen is strongly affected by the 1937 Hindenburg disaster, even though it has been demonstrated that the relevance of hydrogen in the context of this tragedy is highly overestimated [14]. Nevertheless, flammability should be considered when dealing with hydrogen as a fuel [15]. To store hydrogen not only in a save, but also dense form, it can be bound chemically to so-called liquid organic hydrogen carrier (LOHC). These are aromatic components, like dibenzyl toluene, which can be hydrogenated reversibly. When hydrogen is needed, the corresponding alicyclic, hydrogen-rich form is dehydrogenated catalytically. This way hydrogen is released, while the carrier is recovered and can be used again (for details on the LOHC technology refer to the respective literature [16, 17]). Markiewicz et al. evaluated the (eco-)toxicological profile of LOHC materials and concluded that health and environmental risks are similar or even smaller than for conventional fuels [18]. Recently, some of us performed an assessment of system reliability of LOHC-based hydrogen storage for onboard railway transport applications [19].

Even though there already are a number of studies with regard to the safety of alternative fuels for ships, there are still significant gaps in knowledge concerning dependability of the technologies. Especially failures, which do not harm human health, but cause downtime of the system, require further examination. This study tries to close some of the knowledge gaps. It particularly aims at providing a consistent comparison of different alternative fuel concepts with respect to their reliability. The following approaches are evaluated in this study:

\section{- LNG}

- Used in a gas turbine

- Used in an internal combustion engine

- Methanol (internal combustion engine)

- Ammonia (fuel cell)

- Hydrogen stored on an LOHC (fuel cell).

In this study, fuel cells were assumed for producing power from ammonia and hydrogen. Alternatively, it would also be possible (and maybe particularly attractive for the near future) to convert them in dual fuel combustion engines.

The focus of this work is on probability of different failure events and on the severity of their consequences. Redundancies are a powerful way for enhancing reliability. However, they are left out here to avoid masking of potential weak spots that deserve attention.

\section{Methods}

To access the overall failure rates of the different process options, fault tree analysis has been performed. For this task, a component list is set up for each system to include all relevant elements (these lists and flow sheets of all process options are provided in Additional files 1, 2). The system description is simplified to a degree, that all scenarios are treated with the same level of detail. The 
simplified flowsheets are constructed by considering the following principles to achieve models comparable in complexity:

a. For the sake of easy repair or shut down of components in case of an emergency, a flow-regulating valve or a shut-off valve is installed between two system components (e.g., a compressor and a heat exchanger). Both valves are able to isolate dysfunctional system parts.

b. Whenever a parameter (e.g., temperature, pressure, velocity, filling level) for a component is changed, the following component in the flow sheet is a sensor, measuring the new value. Due to the fact, that these sensors are easy to replace, the sequence [system part-sensor] is the only exception from principle (a).

As a measure for the reliability of the different propulsion systems, the failure rate is calculated. The failure rate $\lambda$ indicates the frequency at which a system or component fails to operate. The values for the failure rate are derived from several databases that collect safety data from various chemical applications [20-22]. These databases often provide reliability data in form of a mean time to failure (MTTF). The failure rate $\lambda$ of a component is the reciprocal of the MTTF:

$$
\lambda=\frac{1}{\mathrm{MTTF}} .
$$

Failure rates sometimes vary as a function of time. A common behavior is an enhanced failure probability in the beginning (due to manufacturing errors) and at the end of the lifetime (due to wearout) with higher reliability in between. However, sufficient data for a trustworthy parametrization of time-dependent functions for reliability are not available in most cases. Thus, constant failure rates based on an average value are assumed.

The failure rate for the complete system is calculated by summation of the failure rates for the individual failure events:

$$
\lambda_{\text {total }}=\sum_{i} \lambda_{i}
$$

As a simple example, the piping system consists of a pipe and a screw connection. The potential failure modes for the pipe are leakage, destruction, partial and fuel blockage. For the screw connection, the failure modes are leakage, destruction and gasket fatigue. Each of these failure modes has a specific failure rate of its own. These failure rates are added up to a cumulative failure rate $\lambda_{\text {piping }}$ system
For the analysis provided in this study, the main system components (and their number of occurrence) have been identified for each technology. In the next step, a list of potential failure modes for each of the components has been created. Failure rates have been assigned to each of the failure modes. The sum of these failure rates gives the overall failure rate for the component. Note that some components are used several times within the system. Thus, the failure rate of the individual component has to be multiplied with their number of occurrence (e.g., the overall failure rate related to valves can be higher than the failure rate of a single valve, because even if valve 1 works properly this is not necessarily the case for valve 2). The total failure rate of the system is calculated via Eq. 2 from the different components. Additionally, severity classes (ranging from 1 to 10 ) have been assigned to each failure mode. Severity class 1 represents fault events with negligible consequences. With increasing severity class, consequences become more severe (e.g., minor impact on system functionality in class 4 , major loss of functionality, which is still repairable on sea, in class 7 , risk of serious injuries to humans in class 9 and risk of lethal injuries of complete destruction of the system in class 10). Plotting failure rate over severity class gives the S-P-matrix, which allows to access the criticality of a component.

For all scenarios, a containership has been assumed. Descriptions of the individual processes, S-P-matrixes and lists of all failure modes (with the respective failure rates) considered in this study are reported in Additional files $1,2$.

\section{Results \\ Overall failure rates}

The first step in the discussion of the results should be the overall failure rates. In this step, all failure events are weighted by their probability. Their severity will be taken into account later. The estimated failure rates for the technological options differ by nearly a factor of two (Fig. 1).

It should be kept in mind that modeling of failure probabilities is always associated with a comparatively high margin of uncertainty. High uncertainties in quantifications of overall failure rates are unavoidable, even for well-established technologies. Of course, for new technologies accuracy is even lower. Hence, values should not be seen as precise quantifications, but rather as approximations. Yet, the methodology is still able to provide valuable information.

The difference in the calculated failure rates for the two PEM fuel cell-based scenarios, i.e., ammonia and $\mathrm{LOHC}$, is less than $6 \%$. Hence, these two options can be considered as equivalent within the uncertainty margin 


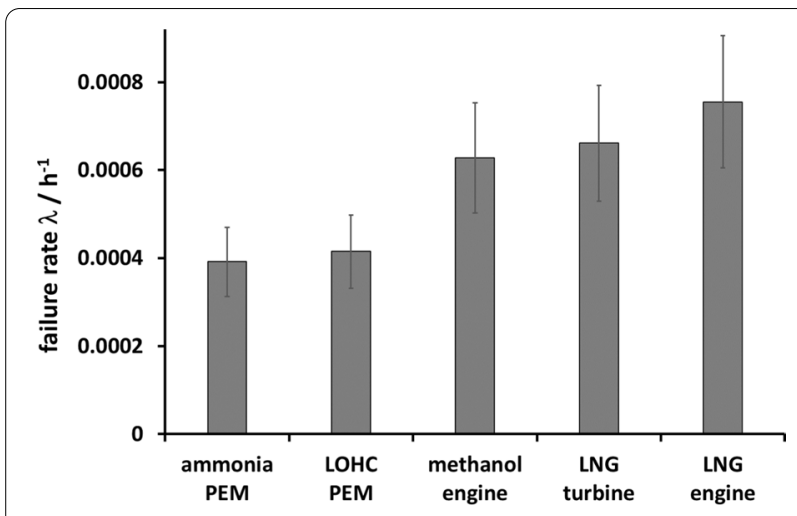

Fig. 1 Comparison of expected failure rates for the main technologies with error bars indicating an uncertainty of $\pm 20 \%$ regarding overall failure rate. Clear differences can be seen in comparison to the methanol and LNG scenarios. The overall failure rates of ships fueled with methanol or LNG are estimated to be in a similar range. Yet, for these scenarios, a higher frequency of failure events is expected than for the two hydrogen technologies. The failure rate of the PEM fuel cell itself was assumed to be the same for both scenarios. However, it should be kept in mind that fuel cell failure will depend on hydrogen purity, which will be different in both scenarios. Purity requirements for fuel cells are complex, because different impurities have very different effects. Here, it was assumed that the regulations of the standards ISO14687 and EN17124 are observed during operation at all times.

In this regard, the failure behavior of fuel cells deserves some further attention. In this study, a constant failure rate over time is assumed for all components. This is reasonable, particularly from a practical point of view: the available amount of data usually does not justify fitting of time-dependent failure probability functions. However, in reality failure probability as a function of time is usually rather pan shaped than constant, as described above. This means that failures are quite likely in the beginning of the lifetime due to potential manufacturing errors. During normal operation, failure rate stabilizes on a lower level. After long operation times, failure rate can increase again due to wear. This non-constant failure probability is quite likely in case of fuel cells. Particularly during early lifetime, fuel cells are currently quite prone to failure due to small manufacturing errors. Nevertheless, fuel cells, which have reached a stable operation mode, are usually quite reliable. Degradation can be observed over time, which requires replacement from time to time. However, this can be monitored and sudden, unpredictable failure is (even though still possible) rather rare.

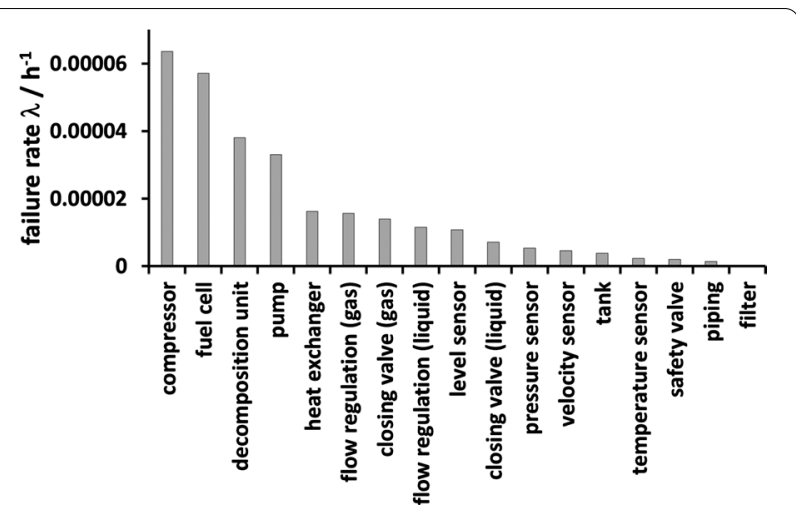

Fig. 2 Failure rates of individual components for the scenario of an ammonia-based propulsion system

\section{Main failure modes}

All systems evaluated in this study consist of a variety of components. While all of them can fail, their probabilities of failure are quite different. Pareto principle says that a small share of causes is responsible for most of the problems. Figure 2 illustrates the contributions of the individual components on the example of an ammonia-based propulsion system.

It strikes that the Pareto principle applies very well. Only four of the components in the systems (less than a quarter of the component types evaluated) contribute two-thirds of the overall failure rate. The huge failure probability associated with compressors is common for mechanical units with moving parts. The main failure mode associated with a compressor is damage on gaskets. In many cases, such damages cause internal rather than external leakage, leading to a slump of performance. In case of the ammonia pump, the failure modes are similar, even though the weightings differ.

Particular attention should also be paid to the decomposition unit. In this device, ammonia is decomposed to release hydrogen for the fuel cell. It processes ammonia under elevated temperature. Damage to the reactor vessel can cause the release of ammonia into the atmosphere of closed rooms onboard the ship.

Concerning valves, it should be taken into account that there are a huge number of valves of different types (e.g., for flow regulation, closing of lines and safety valves). Summing up the failure probabilities of all valves, they contribute about $18 \%$ to the overall failure rate. Putting it that way, valves are already number three in the list of main failure causes.

Summing up all failure probabilities related to sensors (for level control, pressure, etc.), a total contribution of about $8 \%$ to the overall failure rate is estimated. 
The same type of analysis is possible for the other options. The respective diagrams as well as detailed tables on failure modes of the individual components are provided in Additional files 1 and 2. Nevertheless, the methodology discussed so far only evaluates the frequency of failure modes, but does not consider the consequences of the respective failure events. This will be discussed in the following section.

\section{Severity of failures}

Failure events do not only differ in terms of frequency, but also concerning their consequences. A method for describing both aspects together is the S-P-matrix. In this diagram, the frequency of an error (i.e., the failure rate) is plotted over the severity of the consequences of the failure. For quantification of severity, the failure events are grouped in classes. Severity class 1 describes an event with negligible consequences. Severity class 10 includes failure modes that do not only lead to a loss of functionality, but can also cause fatalities. The severity classes between these two extremes describe a gradual increase in relevance of failure consequences (starting with slight losses of partial functionalities over events with full loss of functionality, which can be repaired easily, continuing with failures, which are complicated to repair, and events, which can cause injuries and even death). The failure classes have been defined analogous to the definitions in [19].

First, the S-P-matrix is discussed again for the scenario of an ammonia-fueled ship (Fig. 3). There would be further failure events close to the lower left corner of the diagram. However, they are not taken into consideration, because they are both, rare and of low severity. Consideration is required for elements further to the right or to the upper section of the matrix, and particularly, if both conditions are fulfilled at a time.



Fig. 3 S-P-matrix for the scenario of an ammonia-based propulsion system
Failures of the compressor have been split here into two cases. First, several failure modes can cause a loss of functionality of a compressor (e.g., failure of the shaft, the bearing or the clutch). These failure modes are summarized here as "loss of functionality". If the functionality of hydrogen or oxygen provision to the fuel cell is lost, there will be a loss of power provision. This is classified as severity class 8 . However, there are also potential accidents associated with compressors, which can cause injuries or even fatalities. This is the case for an external breach (i.e., hydrogen is released through a damaged external gasket). Still, such an event is much less likely. Comparing the two types of failure mode, the less severe "loss of functionality" might be considered more relevant than the highly dangerous, but unlikely "external breach" of gaskets of a compressor.

The criticality of the fuel cell is stressed in the matrix, if the failure modes for the compressors are differentiated. Even though the sum of all failure probabilities associated with other components is higher, the failure rate of the fuel cell still requires much attention. This is not only because the fuel cell is located in the upper region of the matrix, but also because it is quite far on the right. A failing fuel cell should not cause fatalities, but a loss of power is still a very problematic loss of functionality for a ship.

Similar criticality can be concluded for the decomposition unit. The probability of a failure might be lower than for the fuel cell. Nevertheless, a damaged vessel of an ammonia decomposition reactor would cause release of ammonia and hydrogen. Consequently, a toxic, corrosive and explosive atmosphere would form.

Sensors on the other hand are of rather low criticality as illustrated by the matrix. Compared to the fuel cell, the compressor or the pump, they are located both, further to the left and further downwards. This means those failures are rather rare and the consequences are limited. Wrong signals from sensor often do not cause a loss of functionality, but only a decrease in performance.

The predicted overall failure rate is lowest for the ammonia-based propulsion system. On the other hand, ammonia is a toxic and corrosive chemical. Thus, many of the more likely failure modes are also associated with a high severity class. For the other alternative propulsion technologies, prioritization of failure is different. Exemplarily, the S-P-matrix for the LNG system with a gas engine will be discussed (Fig. 4; the S-P-matrices for the other option can be found in Additional files 1,2).

For the LNG scenario, criticality of the compressor is similar to the observations for the fuel cell, the compressor or the $\mathrm{NH}_{3}$ decomposition unit in the ammonia scenario. There are several other components exhibiting failure modes with a high severity class, but 


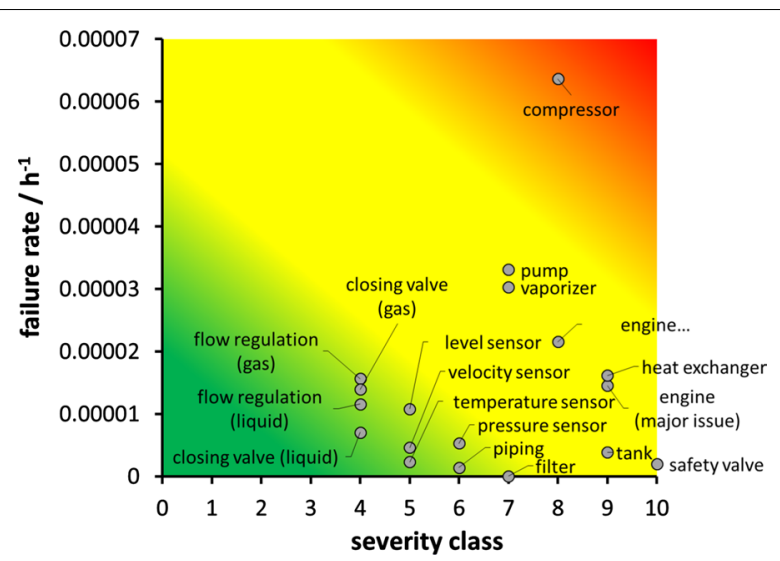

Fig. 4 S-P-matrix for the scenario of an LNG-based propulsion system with a gas engine (a huge share of the overall failure probability is associated with minor issues with the gas engine, outside the range of the diagram) the probabilities are comparatively low. A huge share of the overall failure probability of the system is associated with the gas engine. However, more than $85 \%$ of the failure probability in the engine is associated with failure modes with a severity class of 5 or lower. The main failure mode in this low severity range are defect spark plugs. A failing spark plug leads to a drastic decrease of performance. However, usually total loss of functionality can be avoided and repair is possible, while no further risk for human health or the environment is to be expected. Due to the comparatively high failure rate of spark plugs, the respective data point is outside the diagram. However, criticality is still manageable because of the low severity class.

There is still an explosion risk, if natural gas is released. However, there is no toxicity and corrosion by natural gas is also not to be expected. Consequently, there are less failure modes close to the upper right corner of the S-P-matrix. Overall criticality for the LNG scenario is thus much lower.

Taking the severity of potential faults into account, the slightly lower overall failure rate of the ammonia system is relativized. Particularly the LOHC-based propulsion system is very promising, because it shows low overall failure rates, moderate severity classes and (other than LNG) can be operated with hydrogen from renewable energies. Methanol also proves to be an interesting option. Criticalities (i.e., the product of failure rate and severity class) are comparatively low. Furthermore, green methanol production is possible (even though it is not yet state of the art).

\section{Discussion}

The results in this study are consistent with findings by other groups on individual fuel concepts. For instance, it is shown here that the engine deserves particular attention in case of LNG-driven ships. Wen et al. [9], who used an analytic hierarchical process to evaluate such a ship, also identified engine related components as most critical. Analogously, our findings are consistent with results by Duijm et al. [13], who outlined the necessity of certain measures for ensuring safety on ammonia-driven ships, but showed that ammonia would be a suitable marine fuel regarding safety and reliability.

A decision on the best alternative fuel regarding reliability, resilience and risk has to consider the respective application. Main boundary conditions in this context are:

- Coastal or high-sea operation.

- Long or short distance.

- Cargo or passenger transport.

- Availability of qualified personnel onboard.

- Size of the ship.

Together with aspects such as economics or efficiency, different alternative fuels might be selected.

The present work shows that hydrogen-based fuel concepts (through ammonia decomposition or LOHCs) are very promising. Due to somewhat lower safety risks LOHC-based hydrogen storage seems particularly interesting for passenger transport. However, particularly methanol might also be an option as reliability is also high and similarity to the existing fueling technologies is given.

\section{Conclusion}

Alternative concepts for fueling ships have been evaluated regarding reliability. This analysis included both, the probability of the failure and the severity of the consequences of a fault event. Regarding overall failure rate, ammonia and hydrogen stored on LOHCs have been demonstrated to be very promising options. However, the ammonia option suffers from high toxicity and corrosion risks. Particularly methanol, but also LNG, is therefore still an interesting option for future marine propulsion systems.

\section{Supplementary Information}

The online version contains supplementary material available at https://doi. org/10.1186/s13705-021-00301-9.

Additional file 1. Process descriptions and illustrated results for the different scenarios. 
Additional file 2. Detailed list of failure modes.

\section{Acknowledgements}

Not applicable.

\section{Authors' contributions}

LP performed data acquisition, system design and calculations. KM provided conceptualization and prepared the manuscript. All authors read and approved the final manuscript.

\section{Funding}

Open Access funding enabled and organized by Projekt DEAL.

\section{Availability of data and materials}

All data generated or analyzed during this study are included in this published article [and its additional information files].

\section{Declarations}

\section{Ethics approval and consent to participate}

Not applicable.

\section{Consent for publication}

Not applicable.

\section{Competing interests}

The authors declare that they have no competing interests.

\section{Author details}

${ }^{1}$ Forschungszentrum Jülich $\mathrm{GmbH}$, Helmholtz Institute Erlangen-Nürnberg for Renewable Energy (IEK-11), Egerlandstr. 3, 91058 Erlangen, Germany. ${ }^{2}$ Friedrich-Alexander-Universität Erlangen-Nürnberg, Egerlandstraße 3, 91058 Erlangen, Germany. ${ }^{3}$ Institute of Technical Thermodynamics, University of Rostock, Albert-Einstein-Str. 2, 18059 Rostock, Germany.

Received: 25 February 2021 Accepted: 2 July 2021

Published online: 08 July 2021

\section{References}

1. Chryssakis C. Green ship of the future. In: Encyclopedia of maritime and offshore engineering. 2017. p. 1-9.

2. Aronietis R et al (2016) Forecasting port-level demand for LNG as a ship fuel: the case of the port of Antwerp. J Shipp Trade 1(1):2

3. Srivastava A, Ölçer Al, Ballini F (2018) Decision framework for shipowners to comply with air emission reduction measures: a case study of methanol as a fuel. In: Ölçer Al et al (eds) Trends and challenges in maritime energy management. Springer International Publishing, Cham, pp 415-431
4. Hansson J et al (2020) The potential role of ammonia as marine fuelbased on energy systems modeling and multi-criteria decision analysis. Sustainability 12(8):3265

5. Khooban MH, Vafamand N, Boudjadar J (2019) Tracking control for hydrogen fuel cell systems in zero-emission ferry ships. Complexity 2019:5358316

6. van Biert L et al (2016) A review of fuel cell systems for maritime applications. J Power Sources 327:345-364

7. Koopman RP, Ermak DL (2007) Lessons learned from LNG safety research. J Hazard Mater 140(3):412-428

8. Vanem E et al (2008) Analysing the risk of LNG carrier operations. Reliab Eng Syst Saf 93(9):1328-1344

9. Wan C et al (2014) Facilitating AHP-TOPSIS method for reliability analysis of a marine LNG-diesel dual fuel engine. Int J Perform Eng 10(5):453-466

10. Etemad H, Choi J-H (2017) Fire, explosion and safety Hazard identification (HAZID) of the entire methanol dual fueled system and ship. J Korean Soc Mar Eng 41(10):992-1005

11. Klerke A et al (2008) Ammonia for hydrogen storage: challenges and opportunities. J Mater Chem 18(20):2304-2310

12. Inanloo B, Tansel B (2015) Explosion impacts during transport of hazardous cargo: GIS-based characterization of overpressure impacts and delineation of flammable zones for ammonia. J Environ Manage 156:1-9

13. Duijm NJ, Markert F, Paulsen JL (2005) Safety assessment of ammonia as a transport fuel. Risø National Laboratory, Roskilde

14. Bain A, Van Vorst WD (1999) The Hindenburg tragedy revisited: the fatal flaw found. Int J Hydrog Energy 24(5):399-403

15. Ng HD, Lee JHS (2008) Comments on explosion problems for hydrogen safety. J Loss Prev Process Ind 21(2):136-146

16. Brückner $\mathrm{N}$ et al (2014) Evaluation of industrially applied heat-transfer fluids as liquid organic hydrogen carrier systems. Chemsuschem 7(1):229-235

17. Fikrt A et al (2017) Dynamic power supply by hydrogen bound to a liquid organic hydrogen carrier. Appl Energy 194:1-8

18. Markiewicz M et al (2015) Environmental and health impact assessment of Liquid Organic Hydrogen Carrier (LOHC) systems — challenges and preliminary results. Energy Environ Sci 8(3):1035-1045

19. Uhrig F, Kadar J, Müller K (2020) Reliability of liquid organic hydrogen carrier-based energy storage in a mobility application. Energy Sci Eng 8(6):2044-2053

20. SINTEF (2002) Industrial management. OREDA offshore reliability data handbook. OREDA Participants, Trondheim

21. CCPS (2010) Guidelines for process equipment reliability data, with data tables. Wiley, Hoboken

22. Denson W. Nonelectronic parts reliability data. Reliability Analysis Center. 1991.

\section{Publisher's Note}

Springer Nature remains neutral with regard to jurisdictional claims in published maps and institutional affiliations.
Ready to submit your research? Choose BMC and benefit from:

- fast, convenient online submission

- thorough peer review by experienced researchers in your field

- rapid publication on acceptance

- support for research data, including large and complex data types

- gold Open Access which fosters wider collaboration and increased citations

- maximum visibility for your research: over 100M website views per year

At $B M C$, research is always in progress.

Learn more biomedcentral.com/submissions 